knowledgeable of the Canadian field. This no doubt explains why he has produced a work that is designed for students and researchers, not for professional bibliographers.

Economic History of Canada is sensibly divided into three chronological chapters that are preceded by chapters concerned with 'Interpretive and Bibliographical Sources' and with works that are sufficiently general to defy chronological categorization. Each chapter is in turn subdivided into several topical or regional units. Items are included on a highly selective basis and are designed to enable researchers to learn a great deal about Canadian economic history as well as to gain an understanding of the evolution of the 'state of the art' (in both English and French) in the field of Canadian economic history. Dick's subject expertise has enabled him to select intelligently. The work is thus not filled with the 'junk' that makes many professionally compiled bibliographies a real hazard to neophyte students.

This volume should receive very heavy use in numerous university courses in Canadian economic, social, regional, and even political history. Its superb indices will assist a variety of kinds of researchers, at all levels, to find topics meriting study and to introduce them to available, useful, and representative literature. The seasoned researcher will find listed many items that he has overlooked. Annotations are insightful and carefully structured. They assist the reader to a fuller understanding of Canadian writing in history and the social sciences.

Professor Dick is to be congratulated for presenting us with an uncommonly helpful contribution to Canadian bibliography.

DONALD SWAINSON

Directory of Economic Libraries in Canada. Edited by Irene Lackner and Geraid Prodrick. London: School of Library and Information Science, University of Western Ontario, I977. I vol., unpaged, \$5.00 ISBN 0-7714-0007-I

The Directory prepared by Irene Lackner, of the Economic Council of Canada, and Gerald Prodrick, of the University of Westem Ontario, represents the Canadian contribution to a proposed International Directory of Economic Libraries. The detailed preface repcits on the origin of the project and the procedures employed to gather and process the information.

Three hundred and sixty-seven collections which contain significant holdings in economics are listed. The entries are alphabetically arranged by the name of the unit served by the library, and other information provided includes: the address and telephone and telex rumber; the name of the person in charge; hours of service; conditions of use; services offered; size and level of staff; collection size; and subject areas; when appropriate, additional headings such as special collections, automated operations, and library publications are used. The four indexes allow access by province and city, by personal name, by subject, and by type of library.

This Directory gathers together in one volume information which will certainly be of use to the librarian. Of particular merit is the inclusion of information which sets out conditions of use, ILL policy, and services offered by the library. The economist will be provided with the location of collections and an indication of their strength and specialization.

Unfortunately, two factors detract from the value of the work. Its usefulness is 
threatened by the generalized nature of much of the descriptive material. For the economist, for example, the Atlantic Baptist historical collection would likely be of marginal interest, and few of the twenty-six special collections listed by the University of Toronto appear to be directly related to economics. A more cautious use of the material supplied by the National Library and a more careful pruning are warranted. It is also unfortunate that much of the information is based on data gathered early in 1975 . The information is already dated, and one can only hope that regular updatings are planned for the future.

Some inaccuracies have crept into the indexes; for instance, the reference under agricultural economics to entry 344 is in error. Under the 'International Finance' subject heading, the Scott Library of York University is the only university library to be listed. Initial interest turns to bewilderment when the entry description lists the strongest collections of the Library as English Literature, Sociology, Psychology, and History!

In spite of these criticisms, this work does make a useful contribution to the bibliographical store of knowledge in the discipline. One must hope, however, that future editions will reflect a more discriminating appraisal of the material to be included in the Directory.

PEGGY REUBER

(A former Reference Librarian responsible for the selection of reference materials at the University of Western Ontario, Ms. Reuber is now Head of Cataloguing with the Canadian Institute for Historical Microreproduction, Ottawa.)

\section{Education Resources}

Reference Sources on Canadian Education: An Annotated Bibliography. Compiled by Ethel Auster. oIse Bibliography Series, no. 3. Toronto: Ontario Institute for Studies in Education, 1978. vii, I I4 p., paper, $\$ 5.95$

ISBN 0-7744-0I63-X

A Guide to Educational Records in the Possession of Four City Boards of Education - Hamilton, London, Ottawa, Windsor. Prepared by Edward Jackson. OISE Educational Records Series, no. I2. Toronto: Ontario Institute for Studies in Education, 1978. ii, 60 p., paper, $\$ 2.00$

Ethel Auster's annotated bibliography, Reference Sources on Canadian Education, has been prepared in response to a perceived need for such a source. However, it is not intended as an exhaustive guide to materials about Canadian education; it is a guide that lists some Canadian sources for educational information. Supplementing the Canadian sources are U.s. or British sources; when the number of titles available is considerable, the province of Ontario is covered almost exclusively. While this choice may seem at odds with the aim of compiling a reference work on Canadian education, Auster has a rationale, given that this work was prepared under the auspices of oISE, and she explains this fully in the preface.

There are thirteen categories of material, each given its own chapter, and of these, three - 'Educational Research', 'Directories', and 'Statistical Sources' - are further subdivided. The organization of the text is easy to follow; the bibliography starts with 